\title{
Persona and skin
} Vesna Jovanovska*

\author{
Address: Medical Centre in Kumanovo, Neuropsychiatry Ward, F.Y.R.O.M \\ * Corresponding author
}

\author{
from International Society on Brain and Behaviour: 2nd International Congress on Brain and Behaviour \\ Thessaloniki, Greece. 17-20 November 2005 \\ Published: 28 February 2006 \\ Annals of General Psychiatry 2006, 5(Suppl I):S300 doi:I0.II86/I744-859X-5-SI-S300
}

\section{Background}

The persona as a psychophysical unity, implanted in the system of social relations, is characterised by its specific organisation, resistance (depends on cognitive and affective characteristics) and reaction to all kinds of stress. Is this speciality reflected on the psychosomatic schedule of the skin?

The purpose of this study is to determine the likeness and difference in style of reaction of the patients with determological and psychosomatic illnesses, from the type of urticaria.

\section{Materials and methods}

With 30 patients between the ages of 26-48 (treated for urticaria) the following tests were used: MMPJ, NEO-PI-R and lifestyle. All of our patients found the outer stress new, inexperienced and sudden with very intense intensity.

\section{Results}

By categorical tendency and dimensional analysis is been determined that the patient is characterised with: 1 . General tendency to suffer negative emotions, not to establish and finding it difficult to adapt to new situations and stress, prone to psychological distress, unreal ideas, successive needs and wishes and maladaptive responds. 2. They have a high degree of individual organisation, persistence and motivation in their conduct towards the target. They are with a strong will for success, scrupulous, and punctuate.

A more subtly analysis points at: An increased hostility (anger, madness and frustration), depressiveness (they are easily discouraged, helpless and worried), interpersonally warm, with a fast speed of life, energetic, decisive, their minds function with the tasks, practical, realistic, prefer aesthetic, intellectually curious to new unconventional ideas but in general conformists, in interpersonal tendencies they are characterised with trust, altruism, lenience and mild character based on logical and rational evaluation, competent (with an average self-respect and inner locus of control), with strict consistency to the ethical principles.

The patients differ in: intensity of anxiety, hostility, interpersonal involvedness, basic level of energy, receptiveness of the inner feelings and rating the emotions as an important segment of life, accepting changes, a quest for excitement, positive emotions, an express of authentic feelings, narcissistic needs, working methodology and level of aspiration.

\section{Discussion}

Furthermore, the complexity of the variable characteristics of the persona prone to dermatological and psychosomatic illnesses is questionable. It is more alike the organisation of the persona's features. But, there are also changes. In general, the heterogeneity can be grouped into two groups.

1. A group of more impulsive and manifested level: fast and frequent appearance of allergic manifestations in the form of erythemas on the level of the skin in a period of one hour.

2. A group of gradual erythemisation of the skin, but with consecutive appearance of severe changes and intensified sensation on the pruritus in a period of three to four days.

According to the specific organisation of the personality, this survey emphasises the stress as a specific impact on the body (skin). This study is an evidence of the needs with more basic and holistic treatment of the unit, bearing 
in mind the two different worlds, the psyche (persona) and the skin and taking a simultaneous general and individual approach.

Publish with Bio Med Central and every scientist can read your work free of charge

"BioMed Central will be the most significant development for disseminating the results of biomedical research in our lifetime. " Sir Paul Nurse, Cancer Research UK

Your research papers will be:

- available free of charge to the entire biomedical community

- peer reviewed and published immediately upon acceptance

- cited in PubMed and archived on PubMed Central

- yours - you keep the copyright

Submit your manuscript here:

http://www.biomedcentral.com/info/publishing_adv.asp 